This is a post-print of an article published in Higher Education Policy. The definitive publisher-authenticated version - Jones, Glen A., Skolnik, Michael L., \& Soren, Barbara. (1998). Arrangements for Coordination Between University and College Sectors in Canadian Provinces: 1990-1996. Higher Education Policy, 11(1), 15-27. is available online at: http://www.palgrave-journals.com/hep/index.html

\title{
ARRANGEMENTS FOR COORDINATION BETWEEN UNIVERSITY AND COLLEGE SECTORS IN CANADIAN PROVINCES: 1990-1996
}

\author{
Glen A. Jones \\ Michael L. Skolnik \\ Barbara J. Soren
}

\author{
Higher Education Group \\ Theory and Policy Studies in Education \\ Ontario Institute for Studies in Education of the University of Toronto \\ 252 Bloor Street West \\ Toronto, Ontario \\ M5S 1V6
}

An earlier draft of this paper was presented at the 1997 Annual Meeting of the Canadian Society for the Study of Higher Education, St. John's, Newfoundland. The authors are grateful for the 
financial support provided by the Social Sciences and Humanities Research Council of Canada and the University of Toronto. 


\title{
ARRANGEMENTS FOR COORDINATION BETWEEN UNIVERSITY AND COLLEGE SECTORS IN CANADIAN PROVINCES: \\ 1990-1996
}

\begin{abstract}
A policy question that arises in any jurisdiction where there is some diversity of postsecondary institutional types is whether there should be formal arrangements for coordination among groupings of different type institutions, and if so, what form these arrangements should take. This paper examines questions related to coordination between postsecondary sectors in Canada. We conclude that the Canadian provinces, with one important exception, seem to be content to maintain the center of gravity for coordination at levels below the system, by either facilitating voluntary inter-sectoral arrangements and encouraging interaction between sectors, or leaving these matters largely at the discretion of institutions.
\end{abstract}

\section{Introduction}

Postsecondary education in most countries consists of universities and other types of postsecondary institutions. Often, the various non-university postsecondary institutions - NUPS's as they are called in some jurisdictions - are organized into one or more distinct sectors. For example, in North America the most prevalent form of NUPS is the community college, and in Australia it is the Technical and Further Education institution (TAFE).

A policy question that arises in any jurisdiction where there is some diversity of postsecondary institutional types is whether there should be formal arrangements for coordination among groupings of different type institutions, and if so, what form these arrangements should take. Some reasons for addressing this issue are that such coordination could facilitate student mobility, influence over-all participation rates, clarify the relationships among educational programs offered by different types of institutions, and enable rationalization of resource use between sectors. On the other hand, inter-sector coordination may decrease autonomy of individual institutions, create or reinforce institutional hierarchies, and undermine 
the original, distinctive missions that led to the establishment of different institutional types in the first place.

This paper examines questions related to coordination between postsecondary sectors in one country, Canada. Higher education in Canada consists of at least two distinct sectors: universities and community colleges. As a result of constitutional interpretations, higher education is controlled and administered at the provincial rather than national level. Thus, Canadian higher education can be viewed as a collection of provincial arrangements where each of the ten provinces has a unique network of institutions, policy mechanisms, and policies (Jones, 1997). The paper focuses on a series of questions related to the issue of inter-sectoral coordination within Canadian provinces. Within each province, does the government and relevant agencies attempt to coordinate policies and activities between the university and community college sector? If so, what structural or policy mechanisms are employed to accomplish this coordination? Is inter-sectoral coordination viewed as an important issue within provincial postsecondary systems, or is there a preference for maintaining clear and distinct sectoral boundaries? How does inter-sectoral coordination vary by province and how has it changed over time? The paper will address these questions by reporting data from national surveys of key actors conducted in 1990 and 1996 and discussing our findings in the context of the sectoral approach to higher education coordination.

\section{Institutions, Sectors, and Systems}

In nearly all jurisdictions, institutions of postsecondary education include the university and one or more other institutional types. At what Burton Clark (1983) refers to as the superstructure level of authority, questions emerge concerning the most appropriate 
organizational or coordinating approach. There are three broad types or categories of approach to the organization of the higher education superstructure: institutional, sectoral, or system.

The institutional approach presumes the existence of highly independent, self-regulating institutions and minimal state coordination. Kogan refers to this approach as the "classic" model of university-government relations; the university may receive grants from external sources but it is "responsive to external influences only on its own intellectual and moral recognisances" (1988, p.7). The institutional approach to superstructure arrangements extends this view of universitygovernment relations to all postsecondary institutions within the jurisdiction.

With the sectoral approach, component parts of the postsecondary enterprise are treated differently by the state. These component parts may be defined by institutional type (for example, university versus vocational institute), funding source (for example, private versus public) or some other characteristic. There may be tremendous differences in the approach to coordination by sector, such as a highly autonomous, little-regulated university sector and centrally coordinated technical institutes. Coordinating mechanisms, policies, and funding approaches will be sector-specific.

The system approach treats all parts of the postsecondary enterprise as components of a whole. There may be a variety of institutional types, and even clear sectoral distinctions, but the central emphasis is on system-wide planning and coordination. While many policy matters may be left in the hands of individual institutions or sectoral structures, a system coordinating agency or board possesses the capacity to plan and coordinate system-wide matters and resolve conflicts among institutions and sectors.

While each approach illustrates a different way of coordinating increasingly complex postsecondary arrangements, it should be noted that there are few examples of jurisdictions that 
operate "pure" versions of these approaches. Differences in institutional types, sectoral definitions, system boundaries, and jurisdiction-specific political factors have led to a multitude of variations based on elements of these three broad themes.

At the same time, however, it is clear that issues related to coordination between institutional types within higher education are relevant to all three broad approaches, but the means of facilitating or encouraging coordination differ by approach. There is no mechanism for coordinating matters that transcend institutional type within the institutional approach, so coordination can only take the form of voluntary agreements among institutions or between academic or administrative units within different institutions. In contrast, one might find a variety of different arrangements at different levels of the higher education enterprise within the systems approach. Institutions may enter into bilateral agreements, sectors may create structures and mechanisms to deal with inter-sector issues, and system-level mechanisms will have the capacity to coordinate activities between institutions, sectors, and for the system as a whole. The sectoral approach, however, represents an interesting challenge in terms of facilitating these types of arrangements. In this approach, voluntary, institutional arrangements are possible, just as they are with the other two approaches, but there is no central mechanism or agency to facilitate systemwide planning and so inter-sectoral coordination would require the development of inter-sectoral mechanisms or approaches without the existence of a central body with a system-wide perspective to catalyse, or facilitate these arrangements or mediate sectoral interests. 


\section{The Canadian Provinces and the Emergence of a Sectoral Approach}

Under the Canadian constitutional arrangements for federation, education is a responsibility of the provinces. While the role of the federal government in postsecondary education is weaker than in most other western federal states (see Brown, Cazalis \& Jasmin, 1992), the Government of Canada has had an influence on the development and evolution of higher education, often under the guise of supporting activities more clearly related to its constitutional responsibilities. While direct federal government support played a major role in the post-World War II expansion of Canadian universities, these initiatives gradually evolved into unrestricted transfers to the provinces. The federal government continues to provide direct support for skills training, under the rubric of its responsibilities for employment; provides funding for research and cultural activities; and operates in a variety of policy areas which intersect with postsecondary education (Cameron, 1997). However, since the 1960s the Canadian provinces have played the central role in providing direct operating support to institutions and in postsecondary legislation, regulation and coordination.

Until the 1960s, provincial governments employed an institutional approach to the coordination of postsecondary education. In the four western provinces, postsecondary education was composed of a single provincial university in each jurisdiction as well as a small number of technical institutes and specialized schools. Even in those provinces where there were multiple universities, as in the central and some eastern provinces, provincial involvement in higher education policy was normally limited to decisions concerning the level of operating support to each institution. There were no mechanisms for sectoral, let alone system, policy.

In response to the perceived need to expand higher education to address increasing demand, a review of postsecondary education took place in every Canadian province at some 
point during the 1960s or early 1970s and these reviews led to two types of provincial initiatives that are of particular importance to this discussion. One was the movement towards sectoral coordination through provincial policies for universities and the related creation of intermediary bodies with responsibilities that differed by province but with a common objective of providing government with advice on university matters. While Britain's University Grants Committee had existed since 1919 and more than half of the American states had some form of coordinating or governing boards for higher education by 1959, no such body existed in any Canadian province until after 1960 (Jones, 1996). Every Canadian province except Newfoundland, with only one university, eventually experimented with some form of intermediary body, usually focusing exclusively on university-sector policy.

The second initiative that was usually related to provincial reviews of postsecondary education was the creation of new non-degree institutions. With the prior existence of one or more universities in every province, governments developed new institutional types to address new and emerging needs within each jurisdiction. The result was the creation of what are commonly referred to as community colleges, but these institutions differed dramatically in their role and mission by province. While all community colleges were assigned a role related to technical/vocational education, the new institutions in British Columbia and Alberta were assigned a university-transfer function where the first two years of university-level education could be taken either at a university or at a community college. Quebec's new colleges were structurally located between the secondary schools and universities. Students moved from secondary school to a CEGEP to either pursue vocational education or complete a required preuniversity program. In Ontario, where the government had recently expanded the university sector so that there was a university in almost every major urban center, the new colleges of 
applied arts and technology (CAATs) were designed to be comprehensive technical/vocational colleges without an explicit university-transfer function. Similar, though less-comprehensive, models emerged in Saskatchewan, Manitoba, New Brunswick, and Prince Edward Island. Newfoundland created community colleges somewhat later, while in Nova Scotia these institutions are still quite new.

These new non-degree institutions were designed to address specific needs identified in each jurisdiction, and they tended to be more heavily regulated by government than the universities, with New Brunswick's direct government control of a single multi-campus community college as perhaps the most extreme example. What became clear, however, was that the community college-type institutions emerged as quite distinct in terms of regulation and coordination from the universities, and no province created a system-level governing or coordinating board or experimented with system-level policy or master planning ${ }^{1}$. What emerged in each province was a postsecondary arrangement involving at least two institutional types where coordinating mechanisms involved either an institutional or sectoral approach. While there were modest changes in provincial policies and structures during the 1970s and 1980s, these basic arrangements were in existence when we conducted our first study in 1990.

\section{Research Approach and Method}

A review of the role and mandate of the Ontario colleges of applied arts and technology was being conducted in 1990. The issue of the relationship between Ontario CAATs and universities was the subject of several background papers (Dennison, 1989; Marshall, 1989; Skolnik, 1989; Stokes, 1989) and received considerable attention within the final report (Vision

\footnotetext{
${ }^{1}$ In some jurisdictions, such as Quebec and New Brunswick, provincial reviews of higher education conducted by task forces or commissions produced reports that resembled master plans.
} 
2000, 1990). This Ontario discussion spurred our curiosity to study arrangements for coordination between university and college sectors across the country.

Our research design was based on two important decisions that grounded our approach, and these decisions also illuminate limitations of our research. The first was to focus our attention on coordination structures and arrangements above the institutional level of authority within the higher education superstructure of each province. There are obviously a plethora of articulation arrangements between institutions based on formal and ad hoc agreements involving joint academic programs, arrangements for cost-sharing, credit recognition, and other objectives, but since our emphasis was on provincial level arrangements we did not seek data from individual institutions and have not attempted to catalog or categorize these initiatives. Instead, the two studies involved questionnaires distributed to provincial government departments responsible for postsecondary education, provincial and regional intermediary bodies, and provincial and regional sectoral committees or associations.

The second was that the study was not intended to be evaluative from a national perspective, even to the point of avoiding a common assumption that inter-sector coordination is a positive phenomenon. Instead, we began with the assumption that each jurisdiction has its own structures, institutional types and priorities and that the studies should attempt to obtain information on whether inter-sector coordination was viewed as an issue of any importance, policy matters that are or should be dealt with through a coordinated approach, if any, and the perceptions of senior officials concerning the success of existing arrangements and the need for change. Our questionnaire, therefore, asked respondents to describe and comment on any existing arrangements, indicate the degree to which the issue is of importance in that jurisdiction, and provide their perceptions of whether the current arrangements should be changed. This approach 
provided us with an understanding of how each of the ten provinces have dealt with a common structural issue and the perceptions of key leaders on this issue.

A report of our 1990 study has already been published (Skolnik \& Jones, 1993). We received responses from 18 of the 28 agencies surveyed (64\%), covering all but one province ${ }^{2}$. In that study we received one unsolicited response from a provincial association of universities which was not listed in our source directories but which had heard about the survey, giving us a total of 19 responses. Responses were received between February and June 1990, providing us with a 'snapshot' of arrangements during that time.

The second study employed the same questionnaire as the first, modified only to the extent of providing the sample population with a copy of our 1993 paper and an indication of our interest in understanding change in coordinating structures and related issues (if any) since 1990. We received responses from 20 (71\%) of the 28 agencies surveyed, though there were several situations where two agencies in the same jurisdiction combined to provide us with a single joint response. For both studies, several respondents provided us with relevant documents to further illuminate our understanding of coordinating structures or activities. Responses were received between February and June 1996, providing us with a 'snapshot' of arrangements during that time as well as an understanding of changes since 1990. In addition, we have updated our discussion based on recent events in several jurisdictions.

While common responses from multiple respondents within the same jurisdiction as well as supporting documentation lead us to believe that we have a clear understanding of the

\footnotetext{
${ }^{2}$ In addition to the ten Canadian provinces, we also sent questionnaires to the territorial governments in the Yukon Territory and the Northwest Territories in 1990 and 1996. Since the territories have community college-type institutions and do not have universities, the issue of inter-sector coordination in the territories focuses on crossjurisdictional relationships. While this paper focuses on provincial arrangements, we have included some relevant findings based on the territorial responses.
} 
structural arrangements and mechanisms for coordination within each jurisdiction, it is important to note that there were cases where two respondents within the same province held slightly different perspectives related to the success of current arrangements and the need for coordination. There is nothing particularly surprising about this phenomenon, since all issues of higher education can be perceived in quite different ways by different individuals, but it does highlight an important limitation in interpreting these responses.

Our presentation of findings is constrained by our undertaking not to report information that could identify individual respondents. The principal effect of this constraint is to limit our capacity to identify provinces which had only one or two respondents in regard to opinion items, though we can refer to general tendencies among groupings of provinces.

\section{Coordinating Structures, Mechanisms or Arrangements}

The Maritime Provinces Higher Education Commission (MPHEC) continues to be the only formal higher education agency with a regional mandate. Founded in 1974, the MPHEC was created to replace the provincial university intermediary bodies existing in New Brunswick, Nova Scotia, and Prince Edward Island. The list of institutions under the purview of the Commission includes all universities in the three provinces as well as one community college and several specialized institutes (Maritime Provinces, 1996). Community colleges in Nova Scotia and New Brunswick are excluded from the mandate of the Commission, and therefore there are no arrangements for regional coordination of university and community college sectors at this level of authority. Issues related to inter-sectoral coordination are left in the hands of the respective provinces.

Turning to the provincial level, a single government ministry or department has the major supervisory responsibility for both universities and community colleges in each province. This 
arrangement clearly holds greater potential for inter-sectoral coordination than in situations where two or more component parts of government have mandated roles for higher education policy, but we found it interesting to note that none of the respondents, including all of those from government, described government as the central agent for inter-sectoral coordination. Instead, formal and informal structures including participation from external or sectoral representatives were viewed as the chief mechanisms for coordination. The role of government tended to be discussed in terms of its capacity to create or encourage the creation of coordinating bodies, or to facilitate coordinating arrangements, rather than one of explicitly regulating or legislating the existence of specific forms of coordination.

It is clear that more provinces had formal province-wide structures for inter-sectoral coordination in 1996 than in 1990. Manitoba appears to be moving towards a system approach to postsecondary coordination, while seven provinces (as opposed to five in 1990) now have intersectoral constituent committees. Nova Scotia appears to be the only province where there has been little attempt at inter-sectoral coordination except in terms of articulation arrangements between institutions. This may be seen as a function of the fact that the community colleges are still in their infancy ${ }^{3}$ and preoccupied with issues associated with sectoral development, while the university sector, under the leadership of the Nova Scotia Council on Higher Education which was established in 1989, has been preoccupied with issues related to sectoral rationalization and restructuring.

Perhaps the most sweeping changes in approach to postsecondary coordination since 1990 have taken place in Manitoba. In 1990 the province had a network of community colleges under the direct regulation of a government department while a Universities Grants Commission 
provided government with advice on university policy and had executive responsibility for determining each university's share of the government-determined sectoral allocation. Aside from articulation arrangements at the institutional level, inter-sectoral coordination was limited to the discussions of an internal government committee composed of senior government officials including officials responsible for the college sector and the Executive Director of the Commission. In 1993 the legal framework for the community colleges was changed to allow for college governing boards and a reduced level of direct government control of college activities. In the same year, a provincial review of postsecondary education recommended a system approach to provincial coordination of higher education. In late 1995 the government created an Interim Transition Committee to develop a policy framework for a new Council on PostSecondary Education, and this Committee was still in place at the time of our 1996 study. The province has now disbanded the Universities Grants Commission and passed legislation creating the new Council with a broad mandate to consider system-wide policy for higher education in Manitoba. While it is too soon to know the impact of these changes on inter-sectoral coordination, these initiatives clearly signal a change in direction from a sectoral approach to a system approach in the coordination of higher education and to date Manitoba is the only province to have moved so far in this direction.

The most common structure or mechanism for inter-sectoral coordination among Canadian provinces are inter-sectoral constituent committees. These committees or councils include representatives from each sector and become a focal point for communication, discussion, and facilitating relationships or agreements between sectors or among institutions within each sector. As we noted in 1990, these committees tend to be of two types: one focusing

\footnotetext{
${ }^{3}$ The Nova Scotia Community College was created in 1988 out of a former network of regional vocational schools
} 
upon broad issues of system planning and development, and attempting to identify and facilitate issues cooperation in regard to any issues which cut across sector boundaries; and the other which concentrates upon matters related to articulation. In the provinces of Alberta, British Columbia, and Quebec, as noted earlier, community colleges have long had an explicit function related to the university sector. Committees which fulfill both these roles exist in all three provinces. It should be noted that Alberta and British Columbia have the greatest diversity of institutional types compared with other provinces, and inter-sectoral constituent committees therefore include representatives from the variety of sectors or unique institutions found in these provinces. All three provinces have committees composed of senior institutional administrators representing various sectors, and in the case of Quebec, including senior government officials, that review broad issues that transcend sectoral boundaries. The Alberta Council on Admissions and Transfer and the British Columbia Council on Admissions and Transfer are examples of committees with inter-sectoral constituent representation that focus on policies and guidelines to facilitate transfer arrangements among postsecondary institutions. Yukon College, the only postsecondary institution in the Yukon, participates in the British Columbia Council on Admissions and Transfer and program articulation and transfer arrangements are facilitated through this interaction.

The relatively new Newfoundland Council on Higher Education appears to have been assigned a role that includes broad inter-sectoral issues as well as articulation. While there were limited structures for coordination in 1990, the province has since been experimenting with university-transfer courses through its network of community colleges. The recent reorganization

and specialized institutes. Development of the College de l'Acadie began in 1992. 
of the college sector under a single board (in a province which has a single university) may have implications for the role of the Council.

New Brunswick’s Commission on Excellence in Education submitted a 1993 report that emphasized the importance of student mobility with postsecondary institutions in that province. One of the bodies established to address this recommendation was the Transfer of Credit Committee, originally facilitated by the MPHEC. This body became a forum for developing a provincial protocol on credit transfer. New Brunswick, like Alberta and British Columbia, now produces an annual guide to credit transfer arrangements within that province.

The situation in Ontario is somewhat more difficult to categorize. There is no intersectoral constituent committee of the sort described above, though the government has provided support for an emergent College-University Consortium that includes representatives from both sectors and has the potential to become a forum for encouraging and facilitating inter-sectoral coordination. One of the first initiatives undertaken by the Consortium Council involved a government allocation of $\$ 1$ million to provide seed money to support new college-university cooperative projects. The Council played the central role in developing criteria, requesting proposals, and making recommendations to government.

At the time of the 1996 study, the Ontario government was in the process of creating the Advisory Panel on Future Directions for Postsecondary Education, and the Panel was asked to make recommendations on ways to improve cooperation between Ontario CAATs and universities. The Panel's final report was released in December of 1996 (Advisory Panel, 1996). The Panel made two recommendations relevant to this discussion: 1) that government continue to encourage (rather than direct) cooperative ventures involving college-university programming and shared services and facilities and 2) that a new advisory committee monitor and assess 
postsecondary education in Ontario. The first recommendation reinforces the current practice of leaving CAAT-university articulation and coordination issues in the hands of the institutions. The second would create the first Ontario continuing committee or agency with a mandate to observe (but not direct) Ontario higher education as a system as opposed to two sectors operating in parallel. To date, the government has not responded to these recommendations.

Prince Edward Island, with only one university and one community college, is the province that comes closest to having an institutional approach to coordination. While a respondent noted the existence of an ad hoc committee involving both institutions, one of the means of facilitating coordination involves the university president sitting as an ex-officio member of the community college board, and vice versa.

Respondents were asked to indicate the extent to which they were satisfied with arrangements for coordination. In 1990, British Columbia, Alberta, and Quebec, the three provinces that had established inter-sectoral structures, were generally satisfied with the level of coordination while other respondents expressed a need for more formalized coordination or were optimistic about plans for the development of new committees or mechanisms. More respondents were satisfied with the current arrangements for coordination in our 1996 study, in large part because of the new initiatives that had been undertaken in the intervening period. In some provinces, respondents noted that it was either too soon to determine whether recent initiatives would be satisfactory or that the arrangements were currently under review.

\section{Coordination: Importance and Issues}

Respondents were asked to rate the importance of developing or improving mechanisms and processes for coordination between university and college sectors, in relation to other issues facing higher education, on a four point scale, as: one of the most important issues to address in 
postsecondary education; of middling importance; one of the least important; or not an important issue at all. In aggregate terms, inter-sector coordination was viewed as a more important issue in 1990 than it was in 1996. In the 1996 study, only 4 respondents indicated that coordination was one of the most important issues to address, and three were from provinces that had established inter-sectoral mechanisms, while six respondents indicated that it was an issue of middling importance and the remaining respondents either felt it was an issue of little importance or did not comment. Changes in the perception of importance of this issue within provinces may be a function of the initiatives that have been recently undertaken, and the belief that these new approaches will assist in resolving inter-sectoral issues. On the other hand, the question was designed to have respondents indicate relative importance compared to other issues, and several respondents indicated that while the jurisdiction is clearly interested in inter-sectoral coordination, there are many other issues that are of higher priority. As one respondent noted:

This issue is very important but a 'context' for reform needs to be developed and sustained within which coordination then becomes achievable.

It is also interesting to note that there was no relationship between satisfaction with existing arrangements and the level of importance placed on this issue. Some respondents that viewed the existing arrangements as quite satisfactory indicated that coordination continued to be one of the most important issues to address, while others suggested that coordination was of middling importance or less. Nova Scotia was the only province where respondents indicated a need for a more formalized structure but where developments in each sector prevented, at least to date, the development of mechanisms for inter-sectoral coordination.

The most important issues associated with inter-sectoral coordination, both for those with formal arrangements and those without, concerned academic matters such as credit transfer, joint 
offerings, program review and approval, admissions, and program articulation. All of these issues concern the academic interface between institutional types (and, in some cases, among institutions within the same sector) and encouraging cooperative activities. One respondent noted that

life long learning and all the emphasis put on it in past years dictates that we ensure that learners receive recognition of all training or courses taken ... that the whole postsecondary system is linked and that the courses/programs become building blocks of the system, not just a particular institution, sector or region.

For some respondents there was a perceived need to further standardize this inter-sectoral interface, while others suggested a need to simply clarify what are, and should continue to be, different arrangements between institutions and unique bi-lateral activities.

A second issue concerns the basic value of communication between sectors. Several respondents noted the importance of discussing matters of common interest and sharing institutional or sectoral perceptions of policy issues. Even where there are significant differences between sectoral interests, communication was viewed as an important objective.

Finally, in describing issues warranting greater inter-sectoral coordination, respondents indicated a range of resource and planning matters in addition to reinforcing the importance of the academic interface. Several provinces noted the possibility of sharing resources, such as facilities, or joint ventures involving bulk purchases or insurance arrangements. Others noted the potential for inter-sectoral planning, common or similar approaches to accountability, enrolment planning or monitoring arrangements, and a clarification of sectoral/institutional roles.

In terms of problems with inter-sectoral arrangements, two shortcomings were noted. One is the basic challenge of working with different organizational structures and institutional cultures in order to determine and accomplish common objectives. At the same time, respondents 
indicated that coordination should continue to be viewed in terms of cooperative activities among institutions and sectors rather than some form of top-down or government controlled activity. Recent developments in Manitoba suggest a possible exception to what was otherwise a clear consensus among respondents. The second shortcoming concerned the degree to which the information shared through inter-sectoral structures is communicated down and through various institutions.

\section{Discussion and Conclusions}

In all jurisdictions with multiple institutions of postsecondary education or with two or more institutional types, the question arises concerning the appropriate approach to coordination. Three broad types of approach can be identified: institutional, sectoral, and system.

In 1972, James Perkins noted:

The center of gravity in higher education is moving upward from the single institution to the coordinating body responsible for a broad range of institutions within a single system (Perkins, 1972, p. iii).

During the period when many governments around the world were employing a systems approach and struggling to rationalize and plan broadly-defined systems of higher education, the center of gravity for the coordination of higher education within Canadian provinces changed very little. In the process of expansion within the 1960s, Canadian provinces generally adopted a sectoral approach with new intermediary bodies designed to coordinate policies for a university sector and the development of a new institutional type, generally referred to as a community college but with structural and functional characteristics that varied by province, which was regulated and coordinated in a quite different way. Canadian provinces did not experiment with system-level planning or create system-wide coordinating or governing boards. 
As to why system-level planning or coordinating arrangements were not tried, we can only offer limited speculation. One factor likely is the great deference to university autonomy shown by governments of all provinces since at least the 1960s. In contrast, the community colleges have been viewed by governments from the outset as instruments of government policy. Given the very different relationship with government enjoyed by the two sectors, and the correspondingly different expectations about the appropriate level of government direction given to the two sectors, many would consider it awkward to place the two sectors under a single planning or coordination mechanism. There is another factor related to, if not underlying, this difference between sectors in regard to their relationship to the government which likely has worked against implementation of the system approach. That is the substantial difference in prestige between the university and community college sectors. As a consequence of this prestige differential, many observers, especially within the university sector, would look askance at any initiative which involved placing institutions from the two sectors under a single policy or planning agency.

The Canadian provinces, therefore, represent interesting case studies in how different jurisdictions have attempted to deal with issues that transcend sectoral or institutional boundaries within the context of a sectoral approach. Provinces where community colleges and other institutional types have been assigned a university transfer or pre-university educational role were the first to develop inter-sectoral committees or structures designed to facilitate communication, especially on issues related to the academic interface between institutional types. Several other provinces have now employed a similar approach by creating a forum or mechanism for dealing with, or at least discussing, inter-sectoral issues. Others have, to date, left issues related to intersectoral coordination in the hands of individual institutions. Manitoba appears to be the only 
province where a system-level approach to coordination may emerge, but it is too early to determine the impact of its new Council on Postsecondary Education in terms of coordination and governance.

Our approach is non-evaluative. We have no way of evaluating the effectiveness or relative success of how different provinces have approached issues related to inter-sectoral coordination, or whether this approach is somehow better or worse than the systems approach that has played such a large role in many American states and other jurisdictions. What is clear is that senior government and sectoral officials in many provinces appear to be reasonably satisfied with inter-sectoral mechanisms that essentially maintain a sectoral approach and the distinctive sectoral structures and arrangements that are associated with this approach to coordination. Aside from Manitoba, the Canadian provinces seem to be content to maintain the center of gravity for coordination at levels below the system, by either facilitating voluntary inter-sectoral arrangements and encouraging interaction between sectors, or leaving these matters largely at the discretion of institutions.

\section{References:}

Advisory Panel on Future Directions for Postsecondary Education (1996) Excellence, Accessibility, Responsibility: Report of the Advisory Panel on Future Directions for Postsecondary Education. Toronto, ON: Ontario Ministry of Education and Training.

Brown, D., Cazalis, P. \& Jasmin, G. (Eds.). (1992) Higher Education in Federal Systems. Kingston, ON: Institute of Intergovernmental Relations, Queen's University.

Cameron, D. M. (1997) The federal perspective. In G. A. Jones Ed., Higher Education in Canada: Different Systems, Different Perspectives pp. 9-29. New York, NY: Garland Publishing.

Clark, B. R. (1983) The Higher Education System. Berkeley, CA: University of California Press. 
Dennison, J. D. (1989) College to University - An Analysis of Transfer Credit Policy and Practice. A background paper prepared for Vision 2000. Toronto: Ontario Council of Regents.

Dennison, J. D. (Ed.). (1995) Challenge and Opportunity: Canada's Community Colleges at the Crossroads. Vancouver, BC: UBC Press.

Jones, G. A. (1996) Governments, Governance, and Canadian Universities. In J. C. Smart Ed., Higher Education: Handbook of Theory and Research (Vol. XI, pp. 337-371). New York, NY: Agathon Press.

Jones, G. A. (Ed.). (1997) Higher Education in Canada: Different Systems, Different Perspectives. New York, NY: Garland Publishing.

Kogan, M. (1988) Government and the Management of Higher Education: An Introductory Review. International Journal of Institutional Management in Higher Education, 12 (1), $5-15$.

Maritime Provinces Higher Education Commission. (1996) Annual Report 1995-96. Fredericton, NB: Maritime Provinces Higher Education Commission.

Marshall, R. A. (1989) College-University Transfer Arrangements Existing in Ontario (Questionnaire results). A background paper prepared for Vision 2000. Toronto: Ontario Council of Regents.

Perkins, J. A. (1972) Preface. In J. A. Perkins Ed., Higher education: From autonomy to systems (p. iii). New York, NY: International Council for Educational Development.

Skolnik, M. L. (1989) How Ontario's Colleges Might Respond to Pressures for the Provision of More Advanced Training. A background paper prepared for Vision 2000. Toronto: Ontario Council of Regents.

Skolnik, M. L. \& Jones, G. A. (1993) Arrangements for Coordination Between University and College Sectors in Canadian Provinces. Canadian Journal of Higher Education, 23(1), 56-73.

Stokes, P. (1989). College Transfer Revisited: A Working Paper. A background paper prepared for Vision 2000. Toronto: Ontario Council of Regents.

Vision 2000: Quality and Opportunity. Final Report. (1990). Toronto: Ontario Ministry of Colleges and Universities. 